\title{
EL DERECHO A LA IDENTIDAD Y LA CONTESTACIÓN DE LA PATERNIDAD
}

\author{
THE RIGHT TO IDENTITY AND THE ACTION TO ESTABLISH \\ PATERNITY
}

Maribel Janett Sipán López ${ }^{1}$

\section{Resumen}

El presente ensayo, tiene como propósito reflexionar acerca de la aplicación del principio del Interés Superior de Niño cuando existen conflictos de intereses o discrepancias de derechos: derecho de identidad del niño vs el derecho de la paternidad jurídica. Los avances científicos y tecnológicos relativos a la prueba genética del ADN, para probar la filiación paternal y maternal, se ha puesto sobre el tapete el problema de la paternidad de los hijos concebidos con mujer casada y su reconocimiento por un tero, teniendo las reglas de los artículos $396^{\mathbf{2}}$ y $404^{\mathbf{0} 3}$ del Código Civil, que cierran la posibilidad de poder impugnar y/o declarar la paternidad de un hijo supuestamente extramatrimonial habido en una relación matrimonial; y de otro lado, el derecho a su identidad que se justifica por el Principio del Interés Superior del Niño, siendo que los atributos esenciales de la persona, ocupan un lugar primordial, como es el derecho a la identidad establecido en el Artículo 2 inciso 1 de la Constitución ${ }^{4}$,el que comprende el derecho a un nombre, a conocer a sus padres y conservar sus apellidos, así como el relativo a tener una nacionalidad y la obligación del Estado a su protección. Consecuentemente, se debe prevalecer los principios que enuncian derechos fundamentales como es el derecho a la identidad de un niño, niña y adolescente, a la verdad biológica, a saber su origen biológico, a su personalidad conforme aparecen en la Convención sobre los Derechos del Niño, en nuestra Constitución Política y en el Código de los Niños y Adolescentes, frente a las disposiciones ya desfasadas de los artículos en mención del Código Civil.

Coordinadora de la Oficina Distrital de Justicia de Paz, Secretaria General de la Oficina Desconcentrada de Control de la Magistratura, Asistente de Juez Superior de Sala Mixta de la Corte Superior de Justicia de Huaura. Abogada y Socióloga, Título Especialista en Justicia Constitucional e Investigadora Jurídica por la Universidad de Castilla - La Mancha, España. Maestría en Derecho Civil con mención en Derecho de Familia-UNIFÉ.

2 Artículo $396^{\circ}$.- Reconocimiento de hijo extramatrimonial de mujer casada

El hijo de mujer casada no puede ser reconocido sino después de que el marido lo hubiese negado y obtenido sentencia favorable

3 Artículo 404․-- Declaración judicial de paternidad del hijo de mujer casada

Si la madre estaba casada en la época de la concepción, solo puede admitirse la acción en caso que el marido hubiera contestado su paternidad y obtenido sentencia favorable.

4 Artículo 2.- Derechos fundamentales de la persona

Toda persona tiene derecho:

1. A la vida, a su identidad, a su integridad moral, psíquica y física y a su libre desarrollo y bienestar. El concebido es sujeto de derecho en todo cuanto le favorece. 
Palabra clave: Interés Superior del Niño, derecho de identidad; paternidad de los hijos concebidos con mujer casada, filiación paternal y maternal, Convención sobre Derechos del Niño.

\section{Abstract}

The purpose of this essay is to reflect on the application of the principle of the Best Interest of the Child when there are conflicts of interest or discrepancies of rights: a child's right to identity $v$. the child's right to legal paternity. The scientific and technological advances related to DNA genetic testing to prove paternal filiation and maternal filiation have put the issue of paternity of children conceived with a married woman and their recognition by a third party on the agenda, along with the provisions set forth under articles 396 and 404 of the Civil Code which preclude the possibility of challenging and/or declaring the paternity of a supposedly extramarital child born within a marital relationship; and, on the other hand, the child's right to identity according to the Principle of the Best Interest of the Child, in which the essential attributes of the person occupy an important place, as is the right to identity enshrined in Article 2, paragraph 1 of the Constitution, which includes the right to a name, to know one's parents and to keep their surnames, as well as the right to a nationality and the obligation of the State to protect them. Consequently, principles regarding fundamental human rights such as the right to identity of a child and an adolescent, to the biological truth, to its biological origin, to its personality as they are established in the Convention on the Rights of the Child, in our Political Constitution, and in the Code of Children and Adolescents must prevail in relation to the already outdated articles mentioned in the Civil Code.

Keywords: Best Interest of the Child, right to identity, acknowledgement of paternity of children conceived with a married woman, paternal and maternal filiation, Convention on the Rights of the Child.

\section{INTRODUCCIÓN}

En vista del avance de la constitucionalidad del derecho (Neoconstitucionalismo), y los avances científicos y tecnológicos relativos a la prueba genética del $\mathrm{ADN}$, para probar la filiación paternal y maternal, se ha puesto sobre el tapete el problema de la paternidad de los hijos concebidos con mujer casada y su reconocimiento por un tercero, teniendo las reglas de los artículos $396^{\mathbf{0} 4}$ y $404^{\mathbf{0} 5}$ del Código Civil, que cierran la posibilidad

Artículo 396‥- Reconocimiento de hijo extramatrimonial de mujer casada

El hijo de mujer casada no puede ser reconocido sino después de que el marido lo hubiese negado y obtenido sentencia favorable.

Artículo 404ㅇ․- Declaración judicial de paternidad del hijo de mujer casada

Si la madre estaba casada en la época de la concepción, solo puede admitirse la acción en caso que el marido hubiera contestado su paternidad y obtenido sentencia favorable. 
de poder impugnar y/o declarar la paternidad de un hijo supuestamente extramatrimonial habido en una relación matrimonial; y de otro lado, el derecho a su identidad que se justifica por el Principio del Interés Superior del Niño y del Adolescente, siendo que los atributos esenciales de la persona, ocupan un lugar primordial, como es el derecho a la identidad establecido en el inciso 1 del artículo 2 de la Constitución ${ }^{6}$, el que comprende el derecho a un nombre, a conocer a sus padres y conservar sus apellidos, así como el relativo a tener una nacionalidad y la obligación del Estado a su protección.

Preliminarmente, consideramos que hoy deben prevalecer los principios que enuncian derechos fundamentales como es el derecho a la identidad de un niño, niña y adolescente, a la verdad biológica, a saber su origen biológico, a su personalidad conforme aparecen en la Convención sobre los Derechos del Niño, nuestra Constitución Política y en el Código de los Niños y Adolescentes, frente a las disposiciones ya desfasadas de los artículos en mención del Código Civil, que por naturaleza fueron promulgadas en el año de 1984, cuando aún en el Perú no estaba en boga la constitucionalidad del derecho, ni mucho menos el desarrollo biomédico de la prueba genética del ADN. Además queremos indicar que la protección del núcleo de la familia matrimonial, se ha venido relativizando poco a poco, tanto en la jurisprudencia como en la legislación peruana, que se ha puesto a tono con la normatividad internacional respecto a los derechos del niño, niña y adolescente. Faltando aún que se modifiquen varios artículos relativos al derecho de familia, como propone Varsi en su propuesta integral de reforma al Libro de Familia (Varsi, 2004). Por lo que consideramos que el control difuso que declara la constitucionalidad de los principios y derechos fundamentales debe prevalecer sobre aquellas normas del Código Civil mencionado, dando así la jurisprudencia nacional una respuesta justa y oportuna ante tal problema.

Consecuentemente, cabe interrogarnos: ¿Debe prevalecer los derechos fundamentales del niño, niña y adolescente a su identidad y otros, frente a la no impugnación de paternidad o declaración de paternidad? ¿Debe aplicarse el control difuso de constitucionalidad en estos casos? ¿Debe modificarse los artículos $396^{\circ}$ y $404^{\circ}$ y otros del Código Civil?

Artículo 2.- Derechos fundamentales de la persona

Toda persona tiene derecho:

1. A la vida, a su identidad, a su integridad moral, psíquica y física y a su libre desarrollo y bienestar. El concebido es sujeto de derecho en todo cuanto le favorece. 


\section{EL DERECHO A LA IDENTIDAD DEL NIÑO VS. LA PATERNIDAD JURÍDICA: A PROPÓSITO DE LA CASACIÓN NRO. 2726-2012 DEL SANTA.}

\section{Antecedentes:}

Se trata de la Casación N ${ }^{\circ}$ 2726-2012 del Santa publicado en el Diario El Peruano el dos de enero del año dos mil catorce, que aplicando el control difuso declaró inaplicables los artículos $396^{0}$ y $404^{\circ}$ del C.C., haciendo prevalecer el derecho a la identidad de la niña, considerando el principio del Interés Superior del $\mathrm{Niño}^{7}$ así como el estado constante de familia que afirma su filiación.

El hecho es que el padre biológico interpone demanda sobre impugnación de reconocimiento de paternidad contra los esposos Teodoro y Eva (el padre jurídico y su esposa), alegando que producto de su relación extramatrimonial, procrearon la niña, quien fue reconocida por el codemandado Teodoro, cónyuge en ese entonces de la codemandada. Se práctica la prueba $\mathrm{ADN}$ el cual concluye en un $99.9 . . . \%$ que el recurrente es el padre biológico; sin embargo, Teodoro (padre jurídico) contesta la demanda señalando que dentro de su unión conyugal nació su menor hija, y que dentro del plazo legal se hizo el reconocimiento y no sabía que la menor no era su hija y nunca ha negado ser el padre de la niña.

El Juez de primera instancia declara fundada la demanda inaplicando los artículos 396으 y 404o del C.C. por el artículo 2.1 de la Constitución Política del Estado, dejando sin efecto el reconocimiento realizado por Teodoro respecto a la niña mencionada y declarando la paternidad del demandante a favor de la menor, que apelada la sentencia, la Segunda Sala Civil del Santa revoca la resolución y reformándola declaró improcedente la demanda, considerando que está acreditada que la menor es hija nacida dentro del matrimonio y de la madre de la menor, prevaleciendo el artículo $376^{\circ}$ del C.C.; no habiendo impugnado la paternidad ni la voluntad de hacerlo, por lo que prevalece el artículo $376^{\circ}$ del C.C. ${ }^{8}$. El demandante interpone recurso de casación, la Sala Suprema declara nula la resolución de vista argumentando que la Sala Civil no se ha pronunciado sobre la inaplicación de los artículos $396^{\circ}$ y $404^{\circ}$ del C.C, y además el demandante ha invocado el artículo 2.1 de la Constitución Política del Estado, entre otros derechos conexos que la Sala no ha tenido en cuenta. Sin embargo, la Sala lejos de lo estimado por

Es un principio rector guía, que gradualmente se fue incorporando en el sistema jurídico.

Artículo 376.- Impugnabilidad de la filiación matrimonial.- Cuando se reúnan en favor de la filiación matrimonial la posesión constante del estado y el título que dan las partidas de matrimonio y nacimiento, no puede ser contestada por ninguno, ni aun por el mismo hijo. 
el Supremo, decide nuevamente revocar la sentencia del Juez declarándola improcedente, argumentando que quien demanda la impugnación de paternidad no es la hija en referencia, por medio de su representante legal sino más bien el demandante, padre biológico basado en el ADN y que los artículos en referencia no vulneran el derecho constitucional y que no está reconocido el interés para obrar del demandante, en este caso la contestación de paternidad. Posteriormente, la Sala Suprema, aplicando el control difuso declaró inaplicable los artículos $396^{\circ}$ y $404^{\circ}$ del C.C. y consagrando el artículo 2.1 de la Constitución Política del Estado, casando la resolución de vista y confirmando la de primera instancia que declaró fundada la impugnación de reconocimiento de paternidad a favor del demandante.

\section{El Interés Superior del Niño como principio jurídico garantista.}

Es entendido en doctrina como un principio indeterminado y sujeto a variadas interpretaciones, ya sea de orden jurídico como psicosocial (Zuccolillo, 2016).

Tal como ocurre con este tipo de conceptos, el de interés superior es una expresión imprecisa, susceptible de diversas interpretaciones, y el alcance de la misma dependerá de la situación puntual que se analice, conforme lo apunta Grosman (1998).

El concepto de interés superior del niño se conecta con la idea de bienestar "en la más amplia acepción del vocablo, y son sus necesidades las que definen su interés en cada momento de la historia y de la vida" (Kuyundjian de Williams, Patricia, "El traslado del menor a otra provincia y los derechos del progenitor no conviviente. Pautas", RDF 2004-I-135; íd., Grosman, Cecilia, Los derechos del niño en la familia, Universidad, Bs. As., 1998). ${ }^{9}$

En este punto y siguiendo a Cillero, consideramos que el contenido del principio son los mismos derechos de los niños: “... el interés superior del niño es, nada más y nada menos que la satisfacción integral de sus derechos" (Philip Alston, Bridget Gilmour-Walsh, 1997).

Miguel Cillero plantea que la noción de interés superior es una garantía de que los niños tienen derecho a que antes de tomar una medida respecto a ellos, se adopten aquellas que promuevan y protejan sus derechos

Sentencia: Autorización al menor para viajar a España con su madre. Rechazo a Recurso extraordinario de Inaplicabilidad de Ley. El Interés superior del niño. Suprema Corte de Justicia. La Plata - 21 de mayo de 2008. Disponible en Internet: http://www.asapmi.org.ar/publicaciones/jurisprudencia/articulo.asp?id=734 y consultado el 23.08.2016. 
y no las que los conculquen. Así, éste autor considera que esta noción supera dos posiciones extremas: el autoritarismo o abuso del poder que ocurre cuando se toman decisiones referidas a los niños y niñas, por un lado, y el paternalismo de las autoridades por otro. Para el citado autor el concepto del inte'res superior del niño tendría por lo menos algunas funciones y que, a nuestro parecer se refieren: a) Ayudar a que las interpretaciones jurídicas reconozcan el carácter integral de los derechos del niño y la niña; b) Obligar a que las políticas públicas den prioridad a los derechos de la niñez; c) Permitir que los derechos de la niñez prevalezcan sobre otros intereses, sobre todo si entran en conflicto con aquellos". (Martínez, 2015)

El principio del interés superior del niño, es un principio rector guía (Zuccolillo, 2016), que gradualmente se fue incorporando en el sistema jurídico.

Así tenemos, que se encuentra regulado en el Artículo $3^{\circ}$ de la Convención sobre los Derechos del Niño que señala, "1. En todas las medidas concernientes a los niños que tomen las instituciones públicas o privadas de bienestar social, los tribunales, las autoridades administrativas o los órganos legislativos, una consideración primordial a que se atenderá será el interés superior del niño" y en el Artículo IX del Código de los Niños y adolescentes, que señala, "En toda medida concerniente al niño y al adolescente que adopte el Estado a través de los Poderes Ejecutivo, Legislativo y Judicial, del Ministerio Público, los Gobiernos Regionales, Gobiernos Locales y sus demás instituciones, así como en la acción de la sociedad, se considerará el Principio del Interés Superior del Niño y del Adolescente y el respeto a sus derechos."

Éste principio incorpora a los niños como sujetos de Derechos Humanos, esto es, un ser humano con derechos propios como cualquier adulto, quien pertenece a una sociedad con normas de orden público el cual no deben ser transgredidas. Tal es así, que respecto al derecho de identidad tenemos: El art. $7^{10}$ de la Convención sobre los Derechos del Niño establece notoriamente la necesidad de identidad. El art. $8^{11}$ compromete a los Estados partes a tutelar el derecho inalienable e imprescriptible de la identidad de los niños y adolescentes, además señala que, los Estados partes ante la vulneración del derecho a su identidad del niño deberán reponer prontamente tal derecho.

10 “1. El niño será inscripto inmediatamente después de su nacimiento y tendrá derecho desde que nace a un nombre, a adquirir una nacionalidad y, en la medida de lo posible, a conocer a sus padres y a ser cuidado por ellos.

"1. Los Estados Partes se comprometen a respetar el derecho del niño a preservar su identidad, incluidos la nacionalidad, el nombre y las relaciones familiares de conformidad con la ley sin injerencias ilícitas. 2. Cuando un niño sea privado ilegalmente de algunos de los elementos de su identidad o de todos ellos, los Estados Partes deberán prestar la asistencia y protección apropiadas con miras a restablecer rápidamente su identidad." 
"La atención primordial al interés superior del niño a que alude el Artículo $3^{\circ}$ de la Convención de los Derechos del Niño, apunta a dos finalidades básicas: constituirse en pauta de decisión ante un conflicto de intereses y en criterio para la intervención institucional destinada a proteger al niño. El principio proporciona un parámetro objetivo que permite resolver los conflictos del niño con los adultos que lo tienen bajo su cuidado. La decisión se define por lo que resulta de mayor beneficio para la menor. De esta manera, frente a un presunto interés del adulto se prioriza el del niño"(SCBA, Ac. 87.832 sent. del 28-7-2004. M., G. R. c/ E., A. I. L. s/ régimen de visitas- CÁMARA DE APELACIONES EN LO CIVIL Y COMERCIAL DE DOLORES. Buenos Aires. 18/03/2008).

Finalmente, éste principio exige al juez, legislador, funcionarios, familia, etc., a que, al momento de resolver o de tomar decisiones debe tener en cuenta primordialmente al interés superior del niño, toda vez que el niño es un sujeto activo de derecho. Siendo así, el interés superior del niño, constituye la herramienta eficaz para otorgar un derecho cuando existe conflicto de intereses de derechos, entre un niño y otra persona o institución. Ello exige que, en los casos sujetos a resolución judicial o administrativa en los que estén involucrados niñas, niñas o adolecentes, se verifique la efectiva promoción de sus derechos; prefiriéndolo frente al rigor formal procesal.

\section{Posturas de solución en la doctrina y en la jurisprudencia}

a) Una primera postura.- La que sostiene la Sala Civil del Santa, argumentado que los artículos $396^{\circ}$ y $404^{\circ}$ son aplicables al caso de autos y no son inconstitucionales porque conforme al artículo $396^{\circ}$ del C.C. establece que el hijo de mujer casada no puede ser reconocido sino después que el marido lo hubiese negado y obtenido sentencia favorable, por lo que la presunción de paternidad no puede ser atacada por un tercero y ésta concuerda con el artículo $376^{\circ}$ del C.C. ya que éste prohíbe contestar la filiación matrimonial de quien tenga a su favor las partidas de nacimiento y matrimonio y la posesión constante de estado, como señala Arias-Schereiber Pezet (2001). Además, la Sala sostiene que estos artículos mencionados son normas válidas que no le reconocen interés para obrar al demandante para interponer una acción contestatoria de paternidad.

b) Una segunda postura.- La esgrimida porelJuezdePrimera Instancia y la Sala Suprema que considera que entre los atributos fundamentales de la persona, el principal es el derecho a la identidad consagrado en el artículo

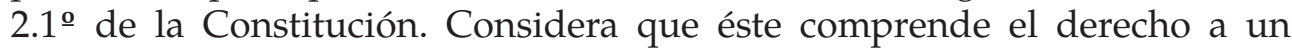
nombre, a conocer a sus padres, conservar sus apellidos, así como el relativo 
a tener una nacionalidad y la obligación del Estado a protegerla, según se estableció en la sentencia recaída en el expediente $\mathrm{N}^{\circ}$ 02432-2005-PH/TC del Tribunal Constitucional.

El principio del Interés Superior del Niño, desarrollada en el artículo 3.1 de la Convención sobre los Derechos del Niño y lo establecido por la Corte Interamericana de Derechos Humanos, consideran que es preciso "ponderar no solo el requerimiento de medidas especiales, sino también las características particulares de la situación en la que se hallan el niño" (Corte IDH. Condición jurídica y derechos humanos del niño. Opinión Consultiva OC-17/02, del 28 de agosto de 2002. Serie A No 17, párrafo 61). Asimismo: “Que el derecho a la identidad debe protegerse de modo preferente, atendiendo a que la vida, la libertad y la identidad conforman una trilogía de intereses que podemos calificar como esenciales entre los esenciales, por ello, merecen una privilegiada y eficaz tutela jurídica", como lo ha señalado Fernández (Fernández Sessarego, 1992, p 22).

Teniéndose en cuenta estos parámetros, se debe inaplicar los artículos $396^{0}$ y $404^{\circ}$ del C.C. y hacer prevalecer el artículo 2.1 de la Constitución Política del Estado concordante con el Principio del Interés Superior del Niño en cuanto se refiere a la identidad filiatoria concordante con su realidad familiar y biológica del menor, procediendo para este caso concreto aplicar el control difuso para que tenga sustento la realidad filiatoria.

c) Postura adoptada.- Adherimos la segunda postura que son lineamientos jurídicos del Tribunal Constitucional y de la Corte Suprema de la República que propugnan que el derecho a conocer la identidad familiar del niño, el derecho a la averiguación y el establecimiento de la verdad biológica $\mathrm{y}$, a conocer sus progenitores es un derecho consagrado en los artículos $7^{\mathbf{0}} \mathrm{y}$

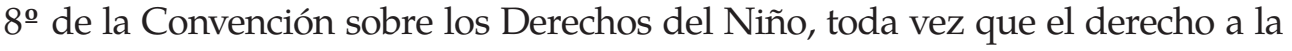
identidad del menor de edad, es un principio universal de su interés superior, plasmado en la Constitución Política del Estado, derecho fundamental que reconoce la trascendencia del derecho a la identidad de los menores y de sus distintas manifestaciones. Además, el artículo 6o de la Declaración Universal de los Derechos Humanos establece: "Todo ser humano tiene derecho, en todas partes, al reconocimiento de su personalidad jurídica" y los artículos $3^{\text {o }}$ y $18^{\text {o }}$ de la Convención Americana sobre los Derechos Humanos de San José de Costa Rica, que establece: "Toda persona tiene derecho a un nombre propio y a los apellidos de sus padres al de uno de ellos..."

Al respecto, el Tribunal Constitucional sostiene que: "La identidad a que se refiere el artículo 2.1 de la Constitución ocupa un lugar esencial entre los atributos esenciales de la 
persona. ... Entre los primeros cabe mencionar los nombres, los seudónimos, los registros, la herencia genética, las características corporales, etc., mientras que entre los segundos se encuentran la ideología, la identidad cultural, los valores, la reputación, etc." (Exp. № 2223-2005-PHC/TC).

En cuanto a la aplicación del principio del Interés Superior del Niño establecida en el Articulo IX del Título Preliminar del Código de los Niños y Adolescentes ${ }^{12}$, en adelante CNA, constituye una regla primaria de ponderación que debe prevalecer frente a otros intereses individuales, complementado con el artículo 3.1 ํㅡ de la Convención sobre los Derechos del Niño, que señala: "En todas las medidas concernientes a los niños que tomen las instituciones públicas o privadas de bienestar social, los tribunales, las autoridades administrativas o los órganos legislativos, una consideración primordial a que se atenderá será el interés superior del niño"13, como así el Tribunal Constitucional, se ha pronunciado acerca del interés superior del niño, señalando: "...Por tanto, constituye un deber el velar por la vigencia de los derechos del niño y la preferencia de su interés resultando que ante cualquier situación en la que colisione o se vea en riesgo el interés superior del niño, indubitablemente, éste debe ser preferido antes que cualquier otro interés" (Sentencia recaída en el Expediente №06165-2005-HC/TC. Fundamento 14).

Como se puede apreciar, los derechos fundamentales de los niños y adolescentes en cuanto se trata de su identidad, verdad biológica y a conocer a sus padres representa una categoría superior fundamental cuando se trata de conocer su real filiación y que ésta debe prevalecer sobre las normas del Código Civil que impiden establecer su derecho materno o paterno filial, en consecuencia el mecanismo de control difuso debe establecerse; sin embargo, el juez al momento de declarar la inconstitucionalidad de una regla para hacer prevalecer un derecho fundamental, debe tener en cuenta a su vez, la ponderación de principios ya que en el caso en estudio efectivamente resultaría así, pero puede darse el caso que: “... No siempre el principio de favor filii o favor recognitionis responde al Interés Superior del Niño, porque no siempre la verdad biológica será la más beneficiosa para el menor o responderá mejor a su interés que la verdad sociológica de la que disfruta en ese momento." (Bermúdez, 2012, p. 434).

Finalmente, para el caso en concreto, se debería tener en cuenta la voluntad del menor, por lo que el derecho del niño, niña y adolescentes de

12 Artículo IX del Título Preliminar del CNA: En toda medida concerniente al niño y al adolescente que adopte el Estado a través de los Poderes Ejecutivo, Legislativo y Judicial, del Ministerio Público, los Gobiernos Regionales, Gobiernos Locales y sus demás instituciones, así como en la acción de la sociedad, se considerará el Principio del Interés Superior del Niño y del Adolescente y el respeto a sus derechos.

13 Convención sobre los Derechos del Niño. Adoptada y abierta a la firma y ratificación por la Asamblea General en su resolución 44/25, de 20 de noviembre de 1989. 
ser oído en un proceso judicial donde está en juego su modo de vivir (apego, sus costumbres, etc.), es aplicar el interés superior del niño, el cual sería determinante para el juez al momento de sentenciar, obviamente tendría que tenerse en cuenta la edad del menor el que debería de considerarse a partir de los 14 años.

\section{CONCLUSIÓN}

Respondiendo a las preguntas formuladas en la introducción tenemos que: a) La limitación en el ejercicio de la acción contestatoria, la cual se restringe al marido, vetando la posibilidad de que el hijo, la madre o en su caso el padre biológico puedan plantear una demanda negatoria de la paternidad. Esta limitación vulnera flagrantemente el derecho fundamental a la identidad que tiene toda persona recogido en el artículo 2.1 de la Constitución Política del Perú, por cuanto la hija por medio de su representante legal no podrá reclamar su verdadera filiación respecto de su progenitor biológico, mientras el esposo de su madre no impugne su paternidad, tal como lo establece el artículo $376^{\circ}$ del C.C. Asimismo las normas $396^{\circ}$ y $404^{\circ}$ del C.C. contraviene la Convención de los Derechos del Niño y las demás normas internacionales sobre derechos humanos suscrito por el Perú, la cual establece que "todo niño tiene derecho a conocer a sus padres y a ser cuidados por ellos". b) Ninguna norma legal puede contravenir a una norma constitucional, como lo es el derecho fundamental a la identidad, reconocido también en el derecho internacional, como un derecho inherente a todo ser humano; por tal motivo, debe ser resguardado, tratándose del caso de un menor donde se debe priorizar el principio del interés superior del niño y adolescente, por lo que debe aplicarse el mecanismo de control difuso para proteger los derechos de los niños. Los preceptos indicados por incompatibilidad constitucional en la sentencia de segunda instancia (Sala Superior Civil del Santa) atenta contra los derechos no sólo de los menores involucrados, sino de aquellos padres que ven soslayada su calidad de tales a consecuencia de lo previsto en tales dispositivos, que priorizan una presunción legal al derecho fundamental a la identidad personal; y c) Finalmente debe modificarse los artículos $396^{\circ}$ y $404^{\circ}$ entre otros del Código Civil.

\section{REFERENCIAS}

Arias -Schreiber Pezet, Max (2001). Exegesis del Código Civil Peruano de 1984. Lima, Perú: Gaceta Jurídica, pág. 108.

Bermúdez Tapia, Manuel (2012). Derecho Procesal de Familia. Lima, Perú: Editorial San Marcos, pág. 434. 
Fernández Sessarego, Carlos (1992). Derecho a la identidad personal. Buenos Aires, Argentina : Editorial Astrea, p. 22.

Mella Baldovino, Ana (2013). Derecho a la identidad prima sobre normas de paternidad matrimonial. Diálogo con la Jurisprudencia. Lima, Perú: Ediciones Gaceta Jurídica, pág19-20.

Varsi Rospigliosi, Enrique (2004). Divorcio, Filiación y Patria Potestad. Lima, Perú: Ediciones Grijley, pág 351 y ss.

Zuccolillo, Marisa (s/f). El Interés Superior del niño en la Convención sobre los Derechos del Niño y otras leyes. Argentina: ASAPMI: Asociación Argentina de prevención del Maltrato Infantil-Juvenil. Recuperado de : http:/ /www.asapmi. org.ar/publicaciones/articulos-juridicos/?id=520. Consultado el 23 de agosto de 2016.

Grosman, Cecilia P. (1998). El interés superior del niño. Buenos Aires, Argentina: Editorial Universidad.

Martínez Ramírez, Miriam (agosto 2015). Interés Superior del Menor. Blog. Por el Interés Superior del Menor en México. México. Recuperado de:/ / sindormealienacionaprentalmexico.blogspot.pe/. Consultado el 23 de agosto de 2016.

Alston, Philip y Gilmour - Walsh, Bridget (1997). El interés superior del niño. Hacia una síntesis de los derechos del niño y de los valores culturales. Argentina: UNICEF

Kuyundjian de Williams, Patricia (s/f). El traslado del menor a otra provincia y los derechos del progenitor no conviviente. Pautas, RDF 2004-I-135; íd., Grosman, Cecilia, Los derechos del niño en la familia, Universidad, Bs. As., 1998, ps. 23 y ss. Recuperado de: $\mathrm{http}$ // /www.asapmi.org.ar/publicaciones/jurisprudencia/ articulo.asp?id=734. Consultado el 23.08.2016.

Corte IDH. Condición jurídica y derechos humanos del niño. Opinión Consultiva OC-17/02, del 28 de agosto de 2002. Serie A N 17 , párrafo 61) Recuperado de : http://www.corteidh.or.cr/docs/opiniones/seriea_17_esp.pdf. Consultado el 23 de Agosto de 2016.

Fecha de recepción: 31 de agosto de 2017 Fecha de aceptación: 19 de setiembre de 2017 